\title{
Estimation of the thermal loads on buildings with CAD systems support Alexis Cordovés García ${ }^{1, a^{*}}$, Gerardo M. Ramos Gordon, b, Jorge A. Mora Aguilar, ${ }^{2, c}$, and Arlys M. Lastre Aleaga ${ }^{3, d}$ \\ ${ }^{1}$ Equinoccial Technological University, Santo Domingo, Ecuador \\ ${ }^{2}$ Pediatric Hospital of Holguin, Cuba \\ ${ }^{3}$ Equinoccial Technological University, Santo Domingo, Ecuador \\ aalexis.cordoves@ute.edu.ec, bgerar092@yahoo.es, cjmora@hpuh.hlg.sld.cu, darlys.lastre@ute.edu.ec
}

Keywords: Thermal loads, CAD system, Geometric information, Radiant Time Series Method

\begin{abstract}
The goal of this paper is the design and implementation of an algorithm for estimating thermal loads in a civil construction, in which the capture geometric information of the architectural plan of a building created in a CAD system (Computer Aided Design), and the calculation of thermal loads in the spaces of the building are integrated. The algorithm was implemented in a software tool that comprises two modules, the first for obtaining geometric information of the building, developed in language AutoLISP programming and the second, in which the calculation of the thermal loads is performed by the method of Radiantes in Time Series (RTS), implemented in Visual Basic for Applications (VBA) in AutoCAD. In this paper, the advantages of integration of both modules, is based on the same graphical environment, to estimate the thermal loads to be removed from a building, and the potential of the application of the RTS method for estimating thermal loads on the other methods, are expressed.
\end{abstract}

\section{Introduction}

The estimation methods of thermal loads intend to model the behavior of different sources of energy and its variation over time as well as the mechanisms of heat transfer (conduction, convection and radiation) and their influence on the building. The magnitude of the thermal load generated in a building depends on: the diversity of sources that provide heat and their interrelationships, the difficulty to accurately calculate a process of unstable nature, the combined effects of the mechanisms of heat transfer, the nature of internal or external loads on spaces, and variability of the thermo-physical properties of building materials [1-3]. The evolution of the estimation methods respond to achieving greater approximation to the real processes involved to obtain an efficient air conditioning system design.

Of the diversity of methods for estimating thermal loads in buildings, in the present investigation was chosen "Radiant Time Series" (RTS) method, developed by the "Load Calculations Technical Committee" ASHRAE from the nonconformity presented with existing methods. Its main merit consist in delivering accurate results with reduced purely subjective data entry, does not require iterative calculations. It is derived from Heat Balance method scientifically considered the most accurate. It delivers hour-by-hour the maximum load in the installation and the energy input from different sources, so it guides the designer how to improve their design [4]. It offers a reasonable compromise between obtaining a rigorous proposal and consideration of subjective aspects such as judgment, experience and appreciation of the engineer [4, 5]. Replace (not eliminate) effectively other simplified methods (without heat balance), such as the Variance Total Equivalent Temperature (TETD) Transfer Functions (TFM) and Temperature Difference Cooling Load / Factor Cooling Load [5]. Although the RTS method is simple in concept, it involves too many calculations and requires implementation in computer assisted systems [5, 6].

The ultimate objective of estimating thermals loads is aimed at the design of an adequate air conditioning system [7, 8]. In this research the goal is to develop and implement an algorithm for 
calculating the thermal loads on the same working environment of the CAD system used to create the architectural plan, and prepare it for further automation of air conditioning system design.

\section{Materials and Methods}

An algorithm for calculating thermals loads by the RTS method it presented, that ensures the designer work integrated within the same CAD system environment. It begins with the characterization of the walls of the spaces to acclimatize and the capture of their geometric data (module 1), (see Fig. 1).

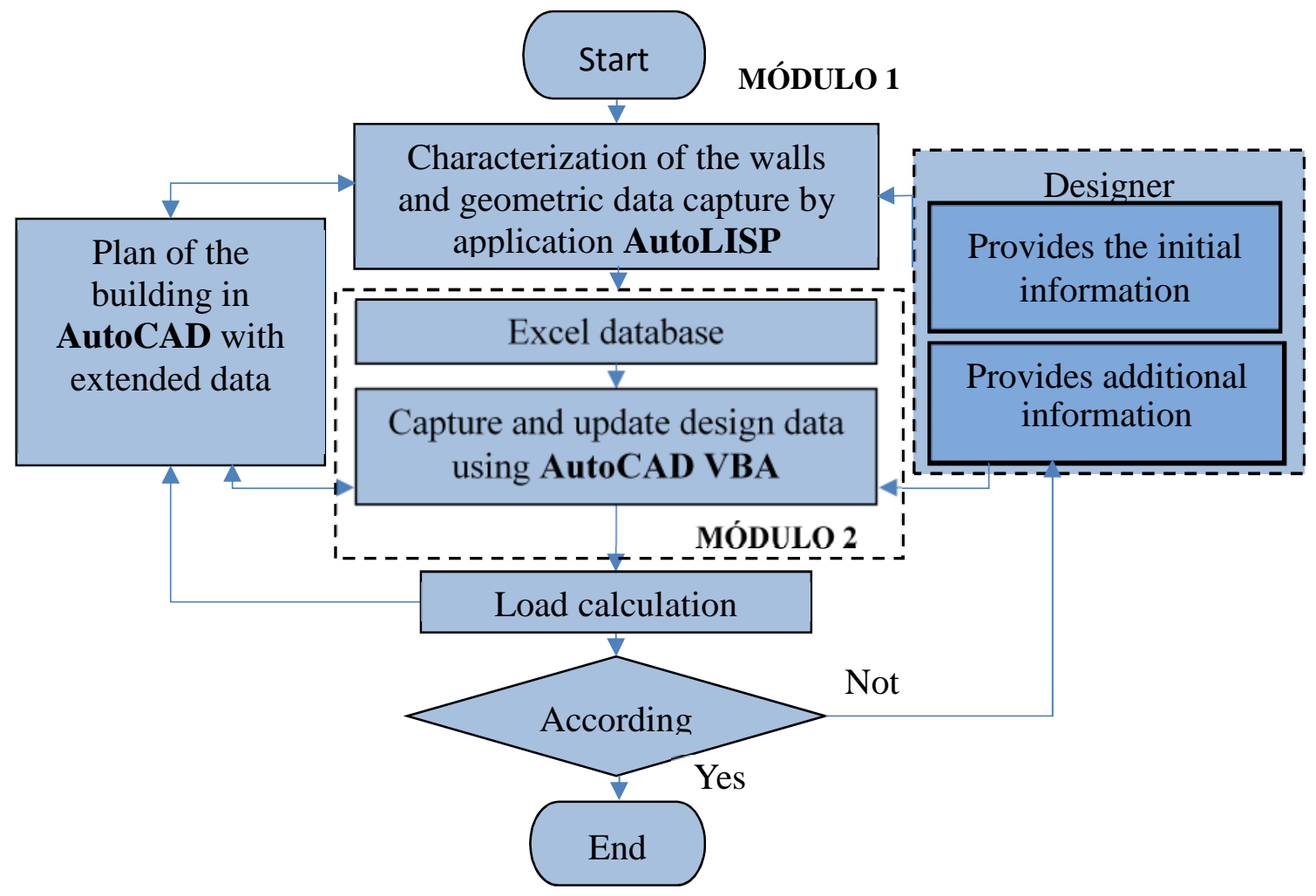

Fig. 1 Algorithm for calculating thermals loads with the CAD system.

The designer identifies a perimetral line (gross line, Fig. 2a), the walls exposed to sunlight and spaces frames to be climatized (gross line, Fig. 2b). The program will process this information and automatically identify the orientation of the walls exposed to the outside, which are interior walls separating, deliver the area of each zone to be conditioned and, the linear dimensions of each of the walls. The information is stored in the database extended of the graphical entities that make up each space to be subsequently used to invoke the module for calculating the thermal loads.

We proceed to the capture of the remaining design data through an application developed in Visual Basic for Applications (VBA) within AutoCAD (See module 2 of Fig. 1). In Fig. 4 the initial application dialog is displayed. Climate information about conditions where the building is located is taken from a database in Excel.

In subsequent dialogues the designer must enter the remaining data on each component of load and interior design conditions for each space or zone. The zone consists of a group of spaces. All information captured of the architectural plane, provided by the designer, or resulting from the corresponding calculation algorithms, is stored in the database extended of the graphical entities, such as shown in Fig. 1. 


\section{N}

Exposed surfaces

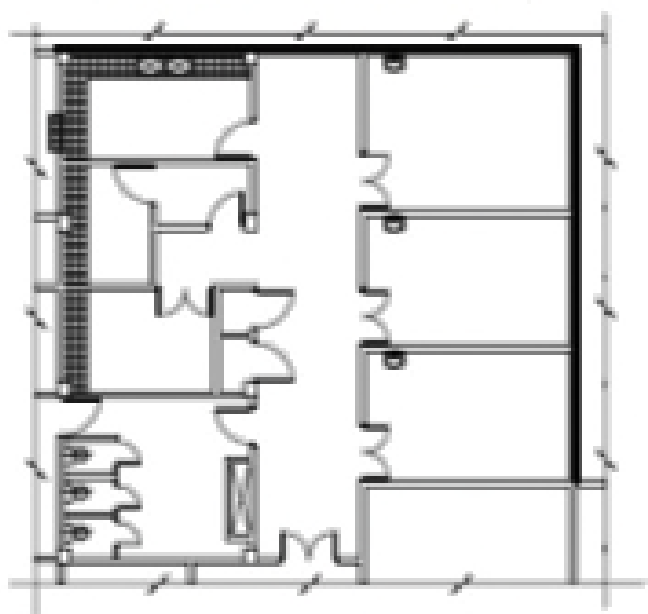

a

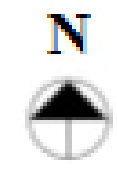

Spaces to be climatized

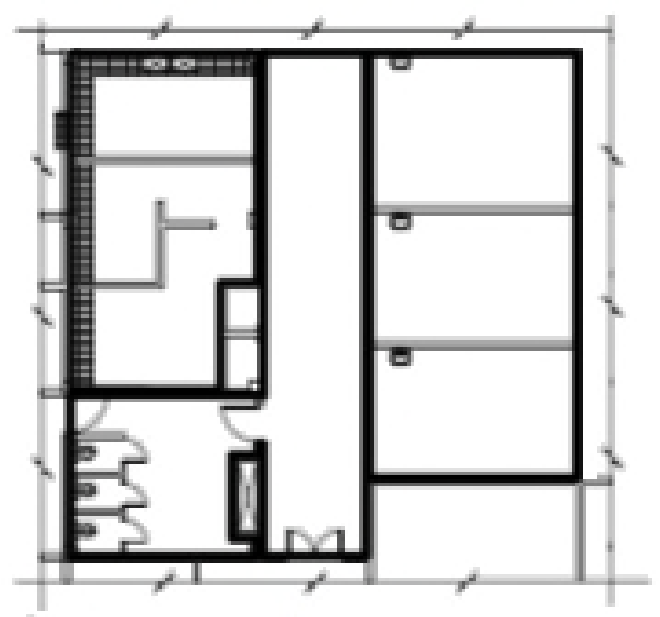

b

Fig. 2 Interaction with the architectural plan of the building to capture information.

Finally, we proceed to the calculation of the thermal load for each space. The thermal load of the building as a whole will be the total of the contributions of each space or zone. If the results do not meet the expectations of the designer, this may introduce amendments in the data and conditions of entry for a new thermal loads calculation to obtain satisfactory results by design criteria and subjective criteria of the designer.

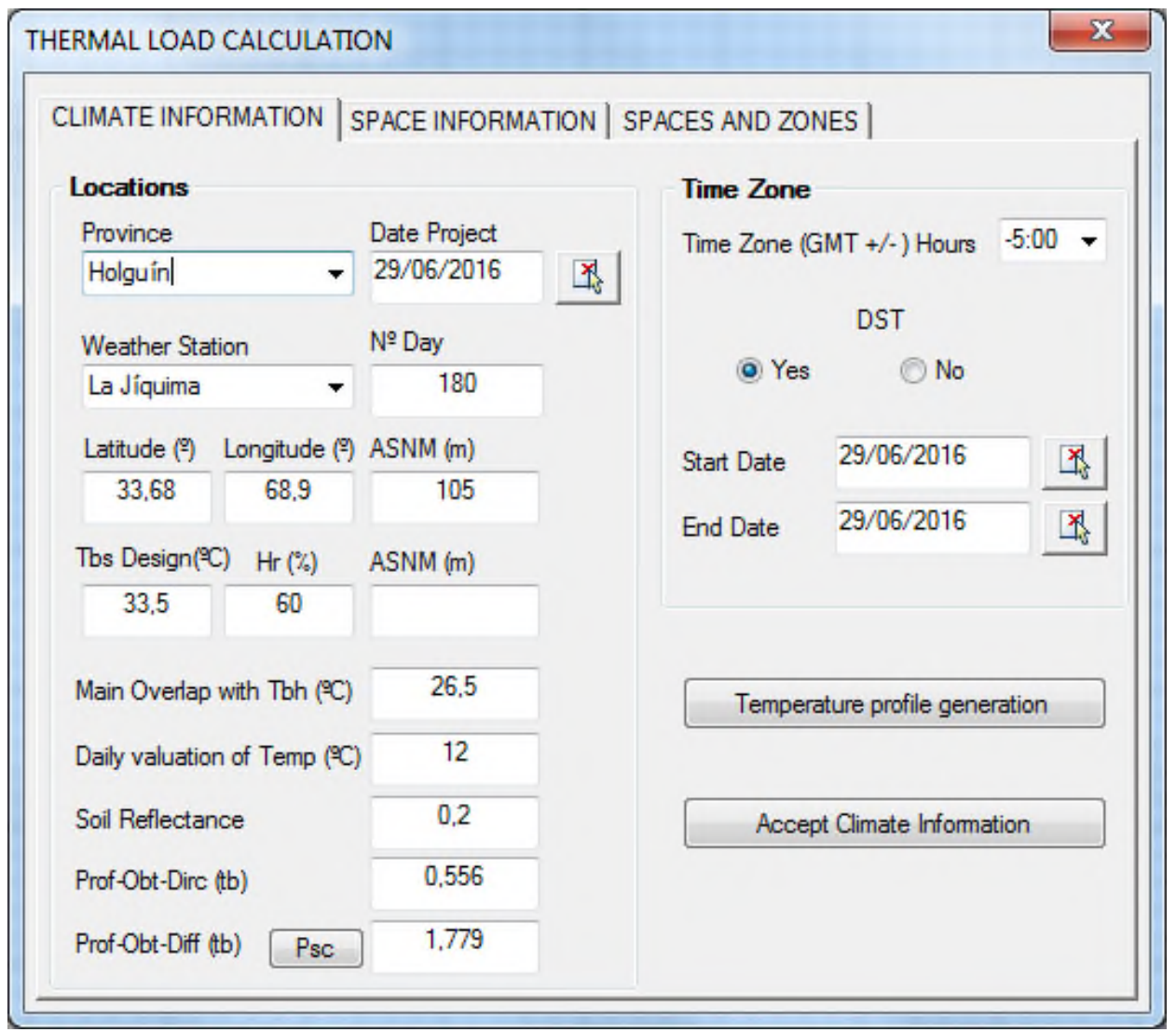

Fig. 3 Calculation module for thermal loads in VBA. 


\section{Comparison of the Results Obtained by the Method of Thermal Balance with those Achieved by Applying RTS Method with the Tool Developed.}

In Fig. 4 the design of the impulsion and expulsion ducts of air conditioning system for a building shown. This solution was obtained by applying the Thermal Balance method for determining the thermal loads. This method is considered the most stringent of existing, also named as the exact solution, which solves the problem of calculation of the thermal loads based on the application of the first law of thermodynamics. The application of this method requires the entry of a large and accurate amount of data to provide reliable results [5, 9].

In order to verify the accuracy of the results obtained with the tool developed in this research, it has been recalculated the thermal loads for the same building, now using the RTS method. To do so, were considered the same construction characteristics of the building, the same sources of thermal contributions to the enclosure and the own assumptions of the project, in order to make the comparison from the same initial data.

The information in Table 1 reveals exterior design conditions (CDE) and interior design conditions (CDI) of the building. The air conditioning system was designed for cold water centralized type, in which a mini-cooled chiller air cooling capacity of $130.26 \mathrm{~kW}(37.0 \mathrm{TR}) 440 \mathrm{v}$, $3 \varnothing, 60 \mathrm{~Hz}, 52 \mathrm{~kW}, 80 \mathrm{~dB}$ noise level and air Treatment Unit (UTA) of 8 rows, with an air flow of $7500 \mathrm{~m} 3 / \mathrm{h}$ (100\% outside) was used as a solution to compensate for the thermal loads generated on the spaces. In addition, four extractions systems using centrifugal extractors on the roof were provided.

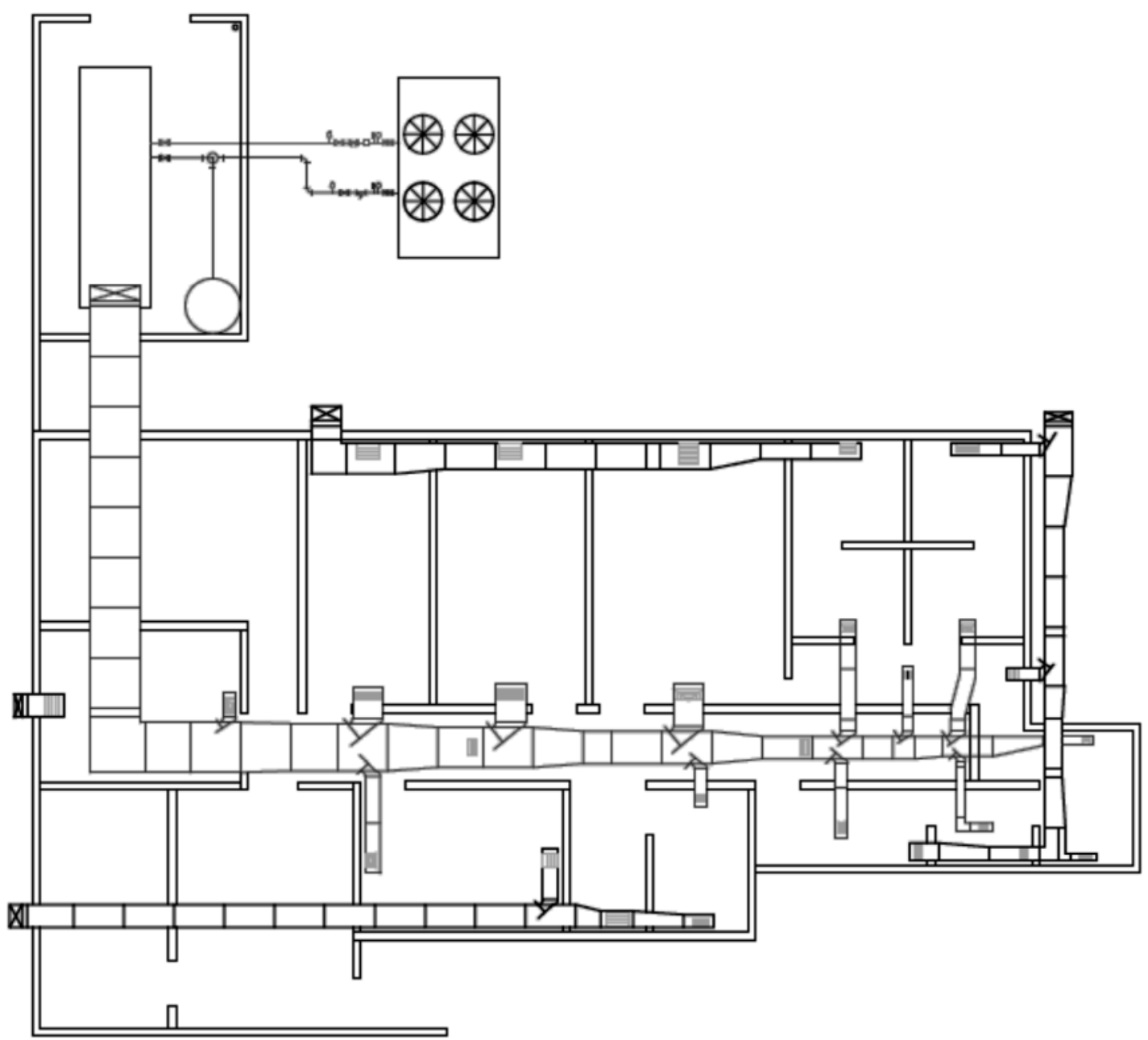

Fig. 4 Building used for comparison of the results obtained by the method RTS respect Heat Balance method. 
Table 1. Design conditions for calculating the thermal loads of the building.

\begin{tabular}{|l|l|l|}
\hline Climatological variables & CDE & CDI \\
\hline Dry bulb temperature $\left({ }^{\circ} \mathrm{C}\right)$ & 34,0 & 22,0 \\
\hline Wet bulb temperature $\left({ }^{\circ} \mathrm{C}\right)$ & 29,0 & 16,7 \\
\hline Dew point temperature $\left({ }^{\circ} \mathrm{C}\right)$ & 27,7 & 13,9 \\
\hline Relative humidity $(\%)$ & 70,0 & 60,0 \\
\hline Atmospheric pressure $(\mathrm{mm} \mathrm{Hg})$ & 760 & 760 \\
\hline Outside air $(\%)$ & 100 & - \\
\hline
\end{tabular}

The results of thermal contributions occur into the enclosure, for each component, are shown in Table 2. As shown, there is a difference of $5.15 \mathrm{~kW}$ (1.5 equivalent TR.) between the solutions obtained by both methods.

Table 2. Comparison of the results obtained by applying the RTS method and the Thermal Balance method to same installation.

\begin{tabular}{|l|c|c|c|c|c|c|}
\hline \multirow{2}{*}{ Load components } & \multicolumn{3}{|c|}{ RTS Method } & \multicolumn{3}{c|}{ Thermal Balance Method } \\
\cline { 2 - 7 } & \multicolumn{3}{|c|}{ Thermal Loads } & \multicolumn{3}{c|}{ Thermal Loads } \\
\cline { 2 - 7 } & $\begin{array}{c}\text { Sensible } \\
(\mathrm{kW})\end{array}$ & $\begin{array}{c}\text { Latente } \\
(\mathrm{kW})\end{array}$ & $\begin{array}{c}\text { Total } \\
(\mathrm{kW})\end{array}$ & $\begin{array}{c}\text { Sensible } \\
(\mathrm{kW})\end{array}$ & $\begin{array}{c}\text { Latente } \\
(\mathrm{kW})\end{array}$ & $\begin{array}{c}\text { Total } \\
(\mathrm{kW})\end{array}$ \\
\hline CT_Lighting & 2,79 & 0,00 & 2,79 & 3,77 & 0,00 & 3,77 \\
\hline CT_People & 0,38 & 0,24 & 0,62 & 0,42 & 0,24 & 0,66 \\
\hline CT_Equipment & 0,59 & 0,00 & 0,59 & 1,00 & 0,00 & 1,00 \\
\hline CT_Exposed walls & 0,29 & 0,00 & 0,29 & 0,38 & 0,00 & 0,38 \\
\hline CT_Exposed ceilings & 5,03 & 0,00 & 5,03 & 6,81 & 0,00 & 6,81 \\
\hline CT_Exposed windows & 0,14 & 0,00 & 0,14 & 0,16 & 0,00 & 0,16 \\
\hline CT_Partitions walls & 1,38 & 0,00 & 1,38 & 2,06 & 0,00 & 2,06 \\
\hline CT_Floor & 1,21 & 0,00 & 1,21 & 2,30 & 0,00 & 2,30 \\
\hline CT_Unexposed windows & 1,06 & 0,00 & 1,06 & 0,64 & 0,00 & 0,64 \\
\hline CT_Infiltration & 0,00 & 0,00 & 0,00 & 0,00 & 0,00 & 0,00 \\
\hline Loads losses & 1,32 & 0,01 & 1,33 & 1,80 & 0,01 & 1,81 \\
\hline Thermal load & 14,19 & 0,25 & 14,44 & 19,34 & 0,25 & 19,59 \\
\hline
\end{tabular}

\section{Results and Discussion}

By applying the RTS method, most of the components that provide thermal loads to building will acquire values of sensible thermal load lower than those obtained with the Thermal Balance method, with the exception of the provision of the windows unexposed, that is upper in $0.42 \mathrm{~kW}$.

The value of the thermal load by applying the RTS method is lower than $5,15 \mathrm{~kW}$ to that achieved by the Thermal Balance method for the case indicated, which will reduce the value of the air conditioning capacity with the following benefits:

- Lower cost of acquisition of equipment to use.

- Lower cost of aggregates used in the installation (electrical conductors, breakers, etc.).

- Lower energy costs during the period of operation of the building.

Although the Thermal Balance method is the most accurate of existing ones, is also the most complex to implement. However, the values obtained by the RTS method reaffirm their qualities to deliver rigorous and accurate results despite being simpler implementation than the Thermal Balance method.

The application developed based on the RTS method offers the designer the possibility of a better interaction with the architectural plan, and greater participation in the decision-making process based on their appreciation and experience. 
The practice in the design of air conditioning systems indicates that in some cases, designers prefer to work with high safety coefficients to support the success of the design solution. However, such a procedure may compromise the costs and energy efficiency of the building in the future.

\section{Conclusions}

In this research the following results, among others, were achieved:

1. An algorithm for calculating thermal loads by the RTS method was presented, which was implemented in a computer application that integrates, in the same CAD environment, capturing information on civil construction and the procedure for calculating thermal loads, propitiating the designer participation with subjective criteria which contribute to obtaining consistent and rigorous results.

2. In implementing the computer tool developed to a study case previously calculated by the method Thermal Balance, satisfactory results were achieved, yielding a value of thermal load less than initially obtained in building, which brings economic benefits to the design of the air conditioning system and for subsequent operation.

3. The computer tool developed, allows you to save relevant information in the extended database of graphic entities architectural plan obtained during the calculation of the thermal load, and that will be useful for the design stage of air conditioning system required.

\section{Reference}

[1] Q. Li, Q. Meng, J. Cai, H. Yoshino, A. Mochida, Predicting hourly cooling load in the building: a comparison of support vector machine and different artificial neural networks. Energ. Convers. Manag. 50(1) (2009) 90-96.

[2] F. Domínguez-Muñoz, J. M. Cejudo-López, A. Carrillo-Andrés. Uncertainty in peak cooling load calculations. Energ. Build. 42(7) (2010) 1010-1018.

[3] F. Causone, S. P. Corgnati, M. Filippi, B. W. Olesen. Solar radiation and cooling load calculation for radiant systems: Definition and evaluation of the Direct Solar Load. Energ. Build. 42(3) (2010) 305-314.

[4] S. Lamas, V. Edwin, Analysis and proposal of a new method of abbreviated simulation for energy certification in residential buildings. PhD thesis, University of Valencia, Spain, (2011).

[5] ASHRAE. Ashrae Handbook Fundarnentals. Atlanta, GA. ISBN 978-1-933742-54-0 / ISSN 1523-7222, (2009).

[6] IU IP SENG. Experimental validation of the radiant time series method for cooling load calculations. Tesis de Maestría, Oklahoma State University, USA, (2002).

[7] S. C.M. Hui, Load Estimation. Ponencia, The University of Hong Kong. Retrieved July 30, 2015 of http://www.powershow.com/view/1174d6MThjN/Dr_Sam_C_M_Hui_powerpoint_ppt_presentation

[8] Arlan Burdick IBACOS, Inc. Strategy Guideline: Accurate Heating and Cooling Load Calculations. Building Technologies Program. U.S. Department of Energy, 2011.

[9] J. C. Rodríguez, L. B Sarias, C. J. Fajardo, V. R. Lugo. Comparative study of the method of calculating thermal load for air conditioning systems on ships. Sci. Tech. Ship. 2(3) ISSN 1909 8642, Colombia, (2008). 